\title{
EL CONSTITUCIONALISMO PERUANO EN LA PRESENTE CENTURIA *
}

Domingo García Belaunde

\section{Preliminar}

El proceso del constitucionalismo peruano empieza, como se Sa e, en 1821, cuando es formalmente declarada la independencia dèi Perú, por el General José de San Martín, aún cuando recién en 1824 en los campos de Ayacucho, la selló en definitiva el Libertador Simón Bolívar. Desde entonces, se han sucedido, a veces con velocidad de vértigo, acontecimientos políticos, sociales y económicos, acompañados en mayor o menor medida, por la dación de lextos y normas legales fundamentales, que conviene tener presente. Pero como quiera que la promulgación de las constituciones no coincide necesariamente con los grandes acontecimientos políticos y sociales, quizá sea conveniente hacer un pequeño recuento histórico-político, antes de entrar al tema que es objeto del presente trabajo.

* En 1987 se cumplieron setenta años de vigencia de la Constitución mexi cana de 1917. Con tal motivo, la Universidad Nacional Autónoma de México realizó diversos homenajes por dicho aniversario, y entre ellos incluyó una publicación colectiva, con colaboradores a nivel mundial, con el título genérico de "El constitucionalismo en las postrimerías del siglo XX", programada en se is volúmenes, de los cuales tres se encuentran actualmente en circulación. El texto que aquí publicamos concluido en Junio de 1987, fue especialmente preparado para esa edición conmemorativa y aquí se le han hecho algunas adiciones y afinamientos, respetando el período cronológico al que se circu nscribe. (D.G.B.). 


\section{Ojeada panorámica}

Como ha quedado dicho, el Perú proclama su independencia de España en 1821, en forma bastante tardía si la comparamos con los hechos similares que se produjeron en otras partes del continente, explicable no sólo por haber sido la Ciudad de los Reyes la sede del poder central virreinaticio en la América Meridional, sino por la ausencia de verdaderas elites que buscaran una separación de la metropoli, aun cuando las individualidades y las gestas aisladas no faltaron tampoco en nuestro país. Uno de los más preclaros precursores, que no llegó a ser del todo separatista, fue Túpac Amaru II, ejecutado bárbaramente en 1781, momento en que puede decirse que se inicia en el ámbito peruano la chispa independentista que sólo cuajaría lustros más tarde. En fín, lo cierto es que con la presencia de San Martin en nuestro suelo, se dan los primeros documentos institucionales, y así tenemos el Reglamento Provisional por él expedido en Huaura el 12 de febrero de 1821 ; al que sigue el Estatuto Provisional de 8 de octubre de 1821, que es continuado por la aprobación por el Congreso Constituyente de las "Bases de la Constitución Política de la República Peruana", que es. si se quiere, el documento fundacional del nuevo estado constitucional peruano, pues aquí se sentaron, por vez primera, los principios relacionados con la organización de los poderes del Estado y la defensa de los derechos individuales, acorde con la filosof ía liberal e iluminista predominante de entonces.

La primera constitución, sin embargo, es la de 1823 (1) que prácticamente tuvo que suspender su vigencia cuando fueron entregados poderes omnímodos al Libertador Bolívar, quien fue llamado al Perú para consumar la independencia nacional. A aquella siguió el texto bolivariano de 1826, destinado por el Libertador a orientar y gobernar todos los países por él liberados, pero que tuvo vigencia efímera.

(1) La Constitución de 1812, si bien furada y aplicada en el Virreynato del Perú y valiosa como antecedente, forma parte, en rigor de nuestra prehistoria constitucional, más que de nuestra historia constitucional propiamente dicha. 
A estos dos primeros documentos constitucionales, que casi no se aplicaron, sucede la Constitución de 1828 , que sienta las bases, a nivel prescriptivo, del nuevo país; primacía del Ejecutivo, coordinación de poderes, autonomía del órgano judicial. presencia de dos Cámaras, derechos individuales clásicos, derecho al sufragio, etc. Esta Carta de 1828, no fue sin embargo de larga duración pues fue sustituida por otra, la de 1834 , a la que sigue el interregno de tres años que significó la experiencia de la Confederación Perú-boliviana (1836-1839) que agrupa a Bolivia, al Estado Nor-peruano y al Estado Sud-peruano. Fracasado este movimiento iniciado desde Bolivia por el General Santa Cruz, se sanciona la Constitución de 1839 que vuelve por los fueros de la República Peruana anterior al in tento confederado; Constitución que dura hasta 1856, aun cuando por breve tiempo, pues es reemplazada por la de 1860 . En 1867 se promulga una nueva Constitución, de signo político contrario a la anterior, pero es derogada al poco tiempo, y la Carta de 1860 recupera su imperio hasta 1919, o más en concreto, 1920 en que se promulga una nueva Carta, la primera del presente siglo, la que es sucedida por dos más; la de 1933 y la vigente de 1979 .

De todo lo anteriormente expuesto, se desprende que a todo lo largo de su vida republicana, el Perú ha tenido varios Estatutos y normas fundamentales que regularon la actividad del Estado, pero sus textos constitucionales formales son tan sólo 11:1823, 1826, 1828, 1834, 1839, 1856, 1860, 1867, 1920, 1933 у 1979.

\section{Una clasificación de las épocas históricas}

A fin de entender la evolución o mejor aún, el proceso de nuestro constitucionalismo en la presente centuria, es conveniente hacer una caracterización de la época, no sólo constitucional, sino histórica, y para ello nada mejor que tomar alguna clasificación que nos pueda servir de referencia. Claro está, que las clasif: zaciones son muchas y muy variadas, y siempre tienen algo de convencional. Así a la altura de 1945, nuestro eminente historiador Jorge Basadre, intentaba varias clasificaciones de nuestra historia republicana, según criterios sociales, políticos, internacionales, etc., en el que podían partirse nuestros diversos períodos, lo que demuestra que es difícil atribuir validez a una sola de ellas, sino que por el 
contrario todas tienen algo de verdad y de convencional (una más reciente clasificación efectuada por el historiador Pablo Macera, divide nuestra historia en dos grandes períodos; uno independiente, que va desde los más leja nos tiempos hasta el siglo XVI, y otro posterior, que sería dependiente, que se inicia con la conquista hispánica y que dura hasta nuestros días). En fin, y para no entrar en mayores honduras, veamos grosso modo una clasificación de orden genérica, adoptada por el mismo Basadre, en la póstuma edición de su Historia de la Repuiblica del Perú (1983) y es la siguiente:

i) La época fundacional de la república (1822-1842);

ii) La falaz prosperidad del guano (1842-1866);

iii) La crisis económica y hacendaria anterior a la guerra con Chile (1864-1878);

iv) La guerra con Chile (1879-1883);

v) El comienzo de la reconstrucción (1884-1895);

vi) La república aristocrática (1895-1919);

vii) El oncenio (1919-1930); y

viii) El comienzo de la irrupción de las masas organizadas en la política (1930-1933).

La clasificación de Basadre es la más completa y minuciosa de las que existen hasta la fecha, motivo por el cual es digna de tomarse en cuenta. No obstante, pueden hacerse algunos reproches a esta clasificación e incluso anotar algunas de sus insuficiencias, que aqui señalamos brevemente:

a) Utiliza criterios distintos para cada período; así, para el segundo periodo emplea un elemento económico; para el cuarto un criterio bélico, para el octavo un criterio politico, etc.

b) Fija períodos que no son inclependientes de los que vendrían después: por ejumplo los períodos quinto y sexto están íntimamente unidos y deberían ser uno solo; por otro lado, no cabe hacer todo un período autónomo sobre el oncenio, por el simple hecho de que durante esos 
once años gobernase al Perú un solo Presidente, el señor Leguía.

c) La clasificación de Basadre concluye el año de 1933, año que él mismo se fijó como final de su investigación histórica, pues no quiso, expresamente, prolongarla más allá, aun cuando en ensayos y artículos dispersos trató aspectos sobresalientes de épocas posteriores (esta limitación, por cierto, hay que respetarla, aun cuando no es definitiva, ya que obedece a un propósito metodológico que se impuso el propio historiador).

Sin ánimo exhaustivo, y siguiendo las huellas de Basadre, podríamos tentativamente reducir ese esquema a sus rasgos más generales y ampliarlo, y tendriamos otro esquema que aquí enunciamos de manera provisional:

i) Determinación de la nacionalidad (1820-1842);

ii) Auge y crisis (1843-1883);

iii) Reconstrucción y progreso (1884-1919);

iv) Dictadura y modernización (1920-1968); y

v) Populismo y democratización (1969-....)

La pregunta que surge de inmediato es cual es la relación entre esta periodificación y los ciclos de nuestra evolución constitucional, ya que los hechos políticos, sociales y económicos son los elementos definitorios de cualquier periodificación histórica.

Si repasamos brevemente los períodos históricos que hemos mencionado, con los diversos textos constitucionales, vemos a primera vista que ellos no coinciden, lo cual, en términos generales comprueba la existencia de un cierto grado de autonomía que tiene lo jurídico, con respecto a lo político y esto último con respecto a lo económico.

4. Los periodos de nuestra historia constitucional

Si a nalizamos nuestros tex tos constitucionales, es factible que 
sobre la base de su análisis, en un primer momento formal, podamos extraer alguna periodificación para los fines de nuestro bosquejo histórico-constitucional.

Así, y si dejamos de lado los Estatutos o Reglamentos de carácter provisorio, podemos constatar que el primer documento constitucional - aun cuando no constitución en estricto sentidoes las Bases de la Constitución Politica de 1822. Estas fueron en realidad las Bases para la Constitución de 1823, pero no lo fueron para las futuras constituciones. Ellas dieron el golpe de gracia a los intentos monarquistas de San Martín al proclamar la República (o sea, la democracia representativa), y los derechos individuales en boga en la época. Proclamaron además su adhesión a la Iglesia Católica en forma excluyente de las demás religiones (que luego otras Cartas dejaron de lado) y los jurados en materia criminal (que no se llegó a aplicar). La primera Constitución en sentido estricto es la de 1823, pero no tuvo ninguna influencia, y murió al nacer, pues su vigencia era incompatible con la presencia de Bolívar y los amplios poderes que se le dieron. La segunda Constitución es la de 1826 , también conocida como constitución boliviana o bolivariana, que creó un congreso con tres cámaras y una presidencia vitalicia, que tuvo vida fugaz. Más bien, fue la Carta de 1828 la que moldeó, en definitiva, el modelo estructural del Estado peruano que ha durado más de cien años. Analizando este tex to de 1828, Manuel V. Villarán ha dicho de ella, que bien puede llamarse la madre de todas nuestras constituciones. Y agrega: "Todas las posteriores dictadas en 1834, 1839, 1856, 1860, 1867 y 1920 (y agregaríamos nosotros la de 1933) son sus hijas legítimas, más o menos parecidas a la madre común. Son como sucesivas ediciones corregidas, aumentadas o reducidas de un libro original". Y concluye: "Esta Constitución puso los durables cimientos de nuestro hogar político". Según Villarán, sus rasgos característicos son: a) reafirmó la forma unitaria del Estado; b) propició la descentralización departamental y administrativa; c) al igual que el modelo norteamericano, previó un presidente con fuerza suficiente para mandar; d) consagró el principio de la bicameralidad; e) estableció el refrendo ministerial, y f) fijó las garantías constitucionales básicas. 
Aun cuando las Constituciones que la siguieron, cambiaron en detalles según la id eología liberal o conservadora que le impusieron las respectivas asambleas constituyentes que las sancionaron, las estructuras básicas duraron por largo tiempo. Las muy liberales, como las de 1856 y 1867 , tuvieron vida breve. Un tex to moderado y sensato como el de 1860 fue, salvo ligeras interrupciones, el más largo de nuestra historia: sesenta años en total, que van de 1860 a 1920. Cuando en 1919 un gobierno de facto quiso justificarse mediante reformas constitucionales, en lugar de reformar la de 1860 , se dio una nueva Constitución; la de 1920, que inaugura el largo período dicta torial de Leguía, que terminará mediante una revuelta en 1930. Sin embargo, las diferencias entre las constituciones de 1860 y la de 1920, son muy escasas, como lo han señalado los estudiosos de aquel periodo, aun cuando apunta en la de 1920 un tímido enfoque social del que carecen las anteriores. Al caer Legura en 1930, las fuerzas políticas se proponen crear una nueva constitución, no porque la de 1920 no fuese buena en la letra, sino porque representaba la voluntad y el designio de una dictadura que se había derrocado. Esto explica la Carta de 1933, que es prácticamente igual a la de 1920. Esta Constitución de 1933, será reemplazada posteriormente por la vigęnte de 1979, que sí representa un cambio sustancial (en lo formal), con respecto a las anteriores. Algunas de estas diferencias son: a) amplia protección de los derechos humanos, acorde con los nuevos vientos de doctrina que soplaban desde la finalización de la Segunda Guerra Mundial; b) afinamiento de la función e integración de los poderes del Estado; c) creación de nuevos órganos constitucionales, en lugar de los tres clásicos, como son el Ministerio Público, el Consejo de la Magistratura, etc.; d) incorporación de lo que la moderna doctrina llama la "Constitución económica", que está ausente en todas las a nteriores constituciones; e) introducción del papel benefactor y empresarial del Estado; f) consagración de la llamada jurisdicción constitucional, en su triple aspecto, el de las libertades, el control de los poderes del Estado que se excedan en la normatividad que expidan, y el reconocimien to de la jurisdicción supranacional.

$\mathrm{Si}$ analizamos estos once textos, y sobre esta base intentáramos hacer una división por períodos de nuestra historia constitucional, ellos podrían ser a lo sumo dos: 
a) el que se inicia con la Constitución de 1828 , y que pone las bases estructurales del Estado peruano, que continuarán todas las constituciones siguientes, hasta la de 1933 inclusive; $y$

b) el iniciado con la vigente Constitución de 1979, que reformula, replantea y moderniza la estructura formal del Estado.

Ahora bien, la clasificación antes expuesta tiene el defecto de destacar tan sólo el aspecto normativo, y si bien no llega a ser falsa, sin lugar a dudas es incompleta, y deja muchos sucesos o acontecimientos en la penumbra. Si combinamos la originalidad (relativa por cierto) de nuestras Constituciones con su vigencia real y efectiva, con los movimientos sociales y políticos que trató de conducir, podríamos hacer una clasificación algo más amplia. Tomando estos elementos, y siguiendo libremente el esquema propuesto por Ricardo Bustamante Cisneros, tendríamos lo siguiente:

a) Primer período: de formación y consolidación institucional (1820 a 1860). Las bases se sientan en 1828, y la experiencia acumulada en estos años difíciles se condensa en la Constitución de 1860 , fruto del consenso de diversas fuerzas y que pudo mantenerse sin problemas hasta 1919.

b) Segundo período: (1860 a 1920). Desde fines del siglo pasado, hasta el fin de nuestra belle ćpoque. Bonanzas, guerra exterior, periodo de reconstrucción y asomo, desde 1912 de inquietudes sociales con la instauración de un gobierno populista, continuado en 1917 y 1918 cuando empezaron, en forma ostensible, las primeras agitaciones universitarias, obreras y campesinas.

c) Tercer período: De 1920 a 1979. Este período, que inicia lo que algunos han llamado nuestro "constitucionalismo social", dura en rigor hasta 1979. La Carta de 1920 es reemplazada por la de 1933 , que es réplica, y al mismo tiempo copia de los principales enunciados de la Carta de 1920. Virtudes de esta última son haber incorporado al 
indio y a las tierras indigenas y campesinas bajo la protección del Estado, haber constitucionalizado el Habeas Corpus (existente por ley especial desde 1897), haber introducido el arbitraje del Estado en materia laboral, entre otros asertos, que desarrollaremos más adelante.

d) Cuarto período: desde 1979 en adelante. Se parte de esta fecha, si bien el origen de la Carta de este año se encuentra en la revolución militar instaurada en 1968, y que culminó doce años después. Esta Constitución es continuación y negación, al mismo tiempo, del gobierno militar, y representa un cambio de lo existente con anterioridad.

Esta cuádruple periodificación, si bien no es perfecta, sin lugar a dudas tiene un mayor alcance explicativo que las anteriores, $\mathrm{y}$ es conveniente utilizarla mientras no encontremos otra mejor.

\section{Los inicios del siglo $X X$}

La presente centuria se inaugura, para el Perú, en 1919, fecha en que acaba, según consagrada expresión del historiador Basadre, la República Aristocrática. Durante los primeros años, e incluso hasta después de concluida la Gran Guerra, vivíamos en pleno siglo XIX. Auge en lo económico; usos señoriales y aristocráticos, ausencia del indio y del obrero en el escenario político del país, predominio de la población rural sobre la urbana, persistencia de varios "perúes", el Perú oficial al lado del Perú real, clasificación que divulgó en el ámbito hispano Costa primero, y luego Ortega y Gasset (la diferencia que en el siglo XIX hicieron escritores franceses entre le pay's légal y le pays réel, que entre nosotros introdujo Víctor Andrés Belaunde en 1918 y Basadre reformula en 1947). Lo que caracterizaría luego al siglo XX nace en realidad durante la década de 1910: preocupación por el problema indigena, protección del Estado a la clase obrera y a la población ind ígena; desplazamiento de la influencia inglesa por la penetración capitalista norteamericana; irrupción de las masas en la vida política del país; renovación de la pintura, la música, la historia, la literatura, el derecho, la filosofía. Todo esto se preparó durante la década del diez 
y empezó a surgir, en ebullición, recién a partir de 1919, coincidiendo con el régimen de Leguía, modernizante y contemporizador, que ayudó a los nuevos cambios para liberarse de la vieja oligarquía que le había impedido el acceso al poder, y que más tarde, iría más lejos de lo que él mismo se lo propuso. Por eso es que puede decirse como ya se ha anotado, que nuestro siglo $\mathrm{XX}$ nace en realidad en 1919, del cual es un pálido reflejo la Constitución sancionada ese año y promulgada en 1920.

\section{Un esquema sobre el siglo veinte}

Desde un punto de vista político y constitucional, hemos dividido el siglo $\mathrm{XX}$ en dos grandes períodos; el que se inicia en 1920, con el régimen dictatorial de Leguía y culmina en 1979; y el que parte de este año, aun cuando sus antecedentes más cercanos se encuentran en el gobierno militar instaurado en 1968.

Desde un punto de vista cronológico estricto podemos advertir en este siglo, a los gobernantes siguientes:

i) Eduardo López de Romaña (1899-1903),

ii) Manuel Candamo (1903-1904),

iii) Serapio Calderón (1904),

iv) José Pardo (1904-1908),

v) Augusto B. Leguía (1908-1912),

vi) Guillermo Billinghurst (1912-1914),

vii) Oscar R. Benavides (1914-1915),

viii) José Pardo (1915-1919),

ix) Augusto B. Leguía (1919-1930),

x) Sánchez Cerro (1930-1933, con interinazgos de terceros),

xi) Oscar R. Benavides (1933-1939),

xii) Manuel Prado (1939-1945),

xiii) José Luis Bustamante y Rivero (1945-1948),

xiv) Manuel A. Odría (1948-1956),

xv) Manuel Prado (1956-1962), 
xvi) Pérez Godoy-Lindley (1962-1963),

xvii) Fernando Belaunde Terry (1963-1968),

xviii) Juan Velasco Alvarado (1968-1975),

xix) Francisco Morales Bermúdez (1975-1980),

xx) Fernando Belaunde Terry (1980-1985),

xxi) Alan García Pérez (1985-1990).

De toda esta relación de veintiún períodos gubernamentales, pueden ser considerados constitucionales por la forma y por el fondo tan sólo a trece: López de Romaña, Candamo, Calderón, Pardo (dos períodos), Leguía (primer período), Billinghurst, Sánchez Cerro, Bustamante, Manuel Prado (sólo su segundo período), Belaunde (en sus dos períodos) y Alan García Pérez. De todos éstos, más del 50\% son anteriores a 1919.

Desde un punto de vista del desarrollo económico, podríamos señalar esquemáticamente las siguientes épocas:

i) de auge: hasta 1929 , con altibajos,

ii) de crisis: 1930 a 1939;

iii) de estabilidad: 1940 a 1950 ,

iv) de auge, con intermitencias: 1950 a 1966 ,

v) de estabilidad: 1967 a 1973 ,

vi) crisis, con altibajos: desde $1973 . .$.

Es importante destacar ciertos hechos como son el auge proveniente de las exportaciones, con que se inicia nuestro siglo; posteriormente, con el crac de la Bolsa de Valores de Nueva York se desencadena la gran crisis que se arrastrará durante toda la década del 30, época en la cual no sólo se estableció la moratoria de la deuda externa, sino que incluso en varios establecimientos públicos ni siquiera se pagaban los sueldos. La Segunda Guerra Mundial trae cierta prosperidad; aumentan las exportaciones tradicionales, como son los minerales que ayudan a la industria de guerra, que luego por factores políticos bajan hasta la década del cincuenta en que vuelven a subir gracias a la guerra de Corea. Luego viene el boom de la industria pesquera, cuyos efectos duran hasta fines de 
la década del sesenta. Posteriormente, entramos en una nueva crisis, cuya solución parece muy lejana, y que tiene su punto de partida en la crisis energética, que empalma con una prosperidad aparente, que luego se derrumba con la presencia de los acreedores que exigen el retorno de una deuda prácticamente impagable. En este estado se encuentra actualmente el Perú y gran parte de los países de la región.

A nivel de influencias constitucionales en este período, podríamos señalar que, aparte de las clásicas influencias norteamericana y francesa que campearon en todo el siglo XIX, en el Perú contemporáneo se hicieron presentes, sobre todo, textos como el mexicano de 1917 (ésto para la Carta de 1920), el alemán de 1919 y el español de 1931( para la Constitución de 1933). En la vigente Constitución de 1979 primaron sobre todo las influencias europeas, especialmente la Constitución española (1978), la italiana (1947) y la Ley Fundamental de Bonn (1949); aparte de los textos internacionales y regionales sobre derechos humanos y algunos latinoamericanos (la Constitución de Venezuela de 1961).

En 1o ideológico-político, se pasó paulatinamente de un Estado oligárquico existente hasta 1919, a un Estado de carácter mesocrático y asistencialista, y por cierto dominador. Durante años este Estado se mantuvo inalterado, aun cuando algo influyeron en mediatizarlo, los movimientos de masas (las fuerzas aprista y comunista). El clima empieza a cambiar a partir de la década de 1950 , y se refleja constitucionalmente recién en 1964, cuando la Constitución de 1933 es modificada para posibilitar la reforma agraria y permitir a los latifundistas expropiados ser pagados en bonos de alcance largo. En 1968 el experimento militar monta un Estado monopólico, intervencionista, reformista, distributivo de arriba a abajo; de corte populista que marca un estilo en la vida política del país. La Carta vigente de 1979 no puede escapar a ese influjo, como una atenta lectura de la misma lo puede corroborar.

En lo relativo a lo económico-social, en la década del treinta se gesta una ebullición desde abajo, que saltará recién en la década del 60 , con las invasiones de tierras por parte de campesinos desposeídos, la guerrilla desatada en 1965 y otras reivindicaciones 
populares y nacionalistas (para hacer del Estado el gran dispensador y administrador de los recursos naturales). Una verdadera eclosión social se anuncia en la década del sesenta, que el gobierno civil, primero, y el militar, después, tratan de encauzar. Como producto de ésto, viene el desfase del Estado, el reclamo de los más necesitados; la constatación de la desigual distribución de la rique$\mathrm{za}$, entre otros factores. La articulación trata de ser salvada con una Constitución de compromiso, como es la vigente de 1979, y con ella empieza a discurrir el país desde hace algunos años. Sus frutos podrán observarse sólo cuando se tenga una mejor perspectiva de los tiempos actuales. En todo caso, historiadores, sociólogos y políticos, han coincidido en señalar, ya desde fines del siglo pasado con Manuel González-Prada, que el Perú está lejos de ser una nación. En fecha reciente, un conocido antropólogo, José Matos Mar, ha precisado que todavía el Perú no ha soldado su doble herencia, la incásica y la hispánica, que será la base de una verdadera nación, y que es la tarea que tiene por delante el Perú de cara ya al siglo XXI.

\section{La historia politica desde 1900 a la actualidad}

E1 inicio del siglo XX coincide con la presidencia de Eduardo López de Romaña, elegido en 1899 y con un mandato de cuatro años, que concluye el 8 de setiembre de 1903. A caballo entre dos siglos, y fruto de la unión política de los dos partidos principales de la época (Partido Civil y Partido Demócrata), Romaña tuvo un periodo sin incidencias; continuó la obra material iniciada por su predecesor, y prosiguió en el arreglo de ciertos problemas limítrofes que tenía pendiente el país, y que todavía darían que hacer a sus sucesores.

A partir de entonces, el Partido Civil, conocido en la jerga política como "civilismo" (fundado por los grandes intereses guaneros y agro-exportadores) se haría del poder casi sin excepciones, hasta 1919, cubriendo un período bastante largo (1899 a 1919).

E1 año 1903, al terminar Romaña su periodo, se parte en dos, como ya hemos dicho, la alianza civil-demócrata. Don Manuel Candamo, elegido presidente en 1903, es víctima de una enfermedad 
imprevista y mal tratada que puso fin a sus días pocos meses después (diciembre de 1904). A la muerte de Candamo, se hizo cargo del mando el segundo vice Presidente de la República, don Serapio Calderón (el primer vice Presidente Lino Alarco había fallecido antes que Candamo).

Las elecciones convocadas poco después, dieron la victoria a José Pardo y Barreda, quien cumplió su período de 1904 a 1908. Pardo era hijo del Presidente Manuel Pardo (1872-1876) y volvería más tarde a la presidencia, como veremos luego. Aspectos importantes de la gestión de Pardo es su preocupación por los problemas limítrofes que nos agobiaron toda la pasada centuria y gran parte de la presente, así como haber impulsado en forma eficaz la instrucción pública, aumentando el control, la reglamentación y construcción de escuelas supervisadas por el Estado. Dio también impulso a la expansión de las líneas del ferrocarril.

A Pardo sucedió Augusto B. Leguía, quien gobernó de 1908 a 1912 , en medio de no pocos problemas y contradicciones. En 1909. tuvo que sofocar un golpe de Estado que hubiera roto la normalidad institucional existente desde 1895. Los hechos son los siguientes: el 29 de mayo de 1909, Leguía fue sacado de Palacio de Gobierno por una multitud que lo paseó por toda la ciudad, y que lo maltrató, exigiéndole su renuncia. Este se resistió con valentía, lo que dio pie para que la custodia presidencial llegase a tiempo a rescatar al Jefe de Estado. Si bien la intentona fue más obra de la audacia que de una intervención premeditada, es indudable que el hecho marcó al período, y sirvió luego a su protagonista para volver años más tarde a la presidencia. Afrontó Leguía problemas de política interna, como los ya referidos, así como de orden externo, pues incluso hubo conflictos en la frontera colombiana (La Pedrera), y al tener problemas con la oposición, aplicó medidas represivas que desprestigiaron al régimen.

Las elecciones fueron agitadas en 1912, cuando Leguía terminó su período, y al no existir los márgenes necesarios para proclamar vencedor de las elecciones, el Congreso, de acuerdo con la Constitución de 1860 entonces vigente, proclamó como Presidente a don Guillermo Billinghurst, que es el primer presidente, con apo- 
yo popular y que sanciona medidas sociales y proteccionistas de nuevo cuño. Aún cuando tímidamente, asomaron en este período algunas protestas sociales, y como consecuencia de ellas, se dictaron las primeras normas sobre protección de los accidentes de trabajo y la jornada de las 8 horas. Sin embargo, el manejo de los problemas internacionales no fue bien llevado, y ocasionó un ambiente hostil contra el mandatario, a lo que hay que añadir sus malas relaciones con el Congreso, todo lo cual preparó un ambiente golpista con apoyo parlamentario, que se concretó el 4 de febrero de 1914, a cargo del coronel Oscar R. Benavides, quien se hizo de la presidencia durante un año, al cabo del cual, mediante justas electorales, fue electo Presidente José Pardo, esta vez en su segundo período (1915-1919).

Iniciada la Primera Guerra Mundial, afrontó el país dificultades de diverso orden, en relación con los depósitos en la banca y las reservas internacionales, que hicieron difícil la administración gubernamental y que sólo al finalizar el gobierno de Pardo, empezó a superarse. A diferencia de su anterior gestión, en su segunda administración Pardo vivió con bonanza, pero no hubo mayor preocupación por hacer obras o arreglar problemas externos.

Al finalizar su mandato, Pardo convocó a elecciones generales. En ellas participó Leguía obteniendo amplia mayoría sobre sus adversarios, la cual debería ser confirmada por el Congreso, de acuerdo a la legislación de la época. Sin embargo, temiendo una eventual maniobra fraudulenta, Leguia dio un golpe de Estado, e inauguró una nueva etapa que tendría larga duración. En lo personal, Leguía se perpetuó en el poder un total de casi once años, promulgó una nueva Constitución en enero de 1920, que si bien con pocas diferencias con respecto a las anteriores, tuvo sin embargo importante repercusión política, como lo veremos más adelante.

En lo político, Leguía significó la cancelación de los partidos históricos (es decir, el Civil, el Demócrata, el Constitucional) que habian gobernado prácticamente sin interrupción desde fines del siglo XIX. Leguía debió concluir su mandato en 1924, pero mediante expresa reforma constitucional se hizo reelegir por un 
período más, que culminó en 1929, año en que nuevamente se hizo reelegir. Se convirtió pues, de facto, en un dictador, que violó continuamente la misma Constitución que había promulgado. Cayó, como veremos, en agosto de 1930. Los aspectos centrales de su administración, pueden resumirse de la siguiente manera:

a) Conculcación de las libertades públicas, en especial de la libertad de expresión, que llegó al extremo de imponer censura a los medios de expresión, y a la incautación de uno de ellos, el diario "La Prensa", que sólo años más tarde fue devuelta a sus propietarios legítimos.

b) Excesivo centralismo, no obstante haber propiciado la creación de Congresos Regionales, que prácticamente no funcionaron. Se eliminó la elección popular de los municipios, y se la reemplazó por Juntas de Notables.

c) Solución de nuestros problemas limítrofes, en fórmulas sujetas a discusión, pero que han dado tranquilidad al país desde entonces. Quedó pendiente el problema limítrofe con el Ecuador, que se zanjó tan sólo en 1942, pero que todavía permanece abierto, por no haberse terminado el proceso de colocación de hitos en 78 kilómetros de fronteras.

d) Creación del Banco de Reserva.

e) Vasto desarrollo de obras públicas, en especial en la ciudad de Lima, a la que transformó por entero, rompiendo moldes urbanos que tenían más de un siglo.

f) Implantación de medidas sociales, que son acompañadas por nuevas manifestaciones artísticas y culturales. En ese período de once años floreció lo que caracterizaría al país durante las décadas siguientes, como es el indigenismo en la literatura y en el arte; así como las nuevas interpretaciones de la realidad nacional (Mariátegui y Haya de la Torre); la literatura (Luis A. Sánchez), la historia (Basadre y Porras), etc. 
g) Política caminera.

h) Política de empréstitos para compensar déficits internos.

Leguía cambió al país. Tras su caída en agosto de 1930, vendrán agitados períodos. Sánchez Cerro forma una Junta Militar, que dura poco tiempo, hasta febrero de 1931. A este gobernante suceden el Arzobispo de Lima, Monseñor Holguín, y luego el Presidente de la Corte Suprema don Ricardo Leoncio Elías, que a la semana es reemplazado por el Comandante Gustavo Jiménez, que es echado por una Junta presidida por David Samanez Ocampo;y todo ésto, en un sólo mes; marzo de 1931. La Junta de Samanez va a marcar época. Intenta la reorganización política del país; para lo cual nombra sendas comisiones, una para que presente un proyecto de Constitución que será presidida por el jurista Manuel Vicente Villarán y otra de reforma de la Ley Electoral. Al mismo tiempo convoca a elecciones generales en octubre de ese año, en las cuales es elegido Sánchez Cerro, quien instala su gobierno en diciembre de 1931, y dura hasta abril de 1933, en que cae asesinado. A partir de la toma del poder por Sánchez Cerro, hasta fines de 1945 , vive el país en medio de grandes incertidumbres, y con seria crisis económica y total apagamiento de las libertades públicas. Es la época también de elecciones dirigidas, de escasez, de falta de crédito en el exterior, de problemas limítrofes y de leyes de emergencia que controlan la actividad política y los medios, con gran número de deportados.

En 1933, al caer asesinado Sánchez Cerro, es elegido para sucederle el general Oscar R. Benavides, quien había desempeñado anteriormente la presidencia de facto, como ya hemos visto (19141915). Benavides es muy sagaz como gobernante, actúa como un dictador, pero deja tras de sí una obra laudable.

Benavides es elegido por el Congreso de ese año, por cuanto en esa época no existía en la Constitución de 1933 la figura de la vice presidencia, que sólo sería incorporada años más tarde. El período de Benavides debió terminar en 1936, fecha en que finalizaba el período para el cual fue designado. Pero el Congreso Constituyente anuló las elecciones de 1936, y prorrogó el mandato de 
Benavides hasta 1939. En el haber de Benavides encontramos una amplia política caminera, la implantación del seguro social, una vasta obra construida (barrios obreros, incluyendo edificios públicos como el local del Palacio de Justicia, actualmente en funciones); la concreción de la carretera Panamericana, la promulgación de importantes dispositivos legales, como el Código Civil de 1936, más tarde reemplazado por el vigente sancionado en 1984 , etc.

A Benavides sucede en el poder Manuel Prado (1939-1945) período que coincide con el desarrollo de la Segunda Guerra Mundial. En este período se zanja, a nivel formal, el último problema limítrofe que mantenía el Perú, al fijarse los límites con el Ecuador en 1942. Prado hizo también obra pública, técnificó el Ejército, tuvo un sano manejo de la administración pública, pero no obstante los moldes constitucionales en los cuales se desempeñó, no fue precisamente un defensor de las libertades ciudadanas.

En 1945 se restauran las libertades políticas en el país, luego que éstas decayeron notablemente en 1932. Si hacemos un análisis de lo que va de siglo, podemos comprobar que la democracia política impera desde fines del siglo pasado, y con algunas intermitencias dura hasta 1920; luego viene un largo período de oscurecimiento de dichas libertades hasta 1930; en donde hay un renacer que sucumbe nuevamente en 1932 y sólo reaparece en 1945, cuando todas las fuerzas políticas actuantes y en vigencia en aquel momento, deciden optar por un solo candidato auspiciado por el recién constituido Frente Democrático Nacional, que lleva a la presidencia a José Luis Bustamante y Rivero. No obstante, este limpio proceso iniciado con tantos auspicios, empieza a naufragar a los dos años (cuando el Presidente se queda sin Cámaras). Un año más tarde, en 1948, es derrocado por la presión de grandes intereses agro-exportadores afectados. Entre las obras de este gobierno, que por lo demás tuvo tan poca oportunidad de actuar; está la política de viviendas para la clase media, en grandes conjuntos residenciales, completando las viviendas obreras que inició en la década anterior el gobierno del general Benavides; así como otras inversiones y el apoyo a la educación.

En 1948 se instaura un gobierno de facto que dura hasta 
1950, año en el cual es elegido Presidente Manuel A. Odría, el mismo que dio el golpe de Estado y que presidió la Junta en 1948. Por eso es que para efectos prácticos, al gobierno de Odría se le sindica como el "ochenio", o sea, el período que corre de 1948 a 1956. Considerándolo hasta esa fecha, el de Odría puede ser el más eficaz de los gobiernos en este siglo, pues fue fecundo en la construcción no sólo de carreteras, sino de edificios públicos, escuelas, viviendas, etc. Como contrapartida, desde el punto de vista político, el régimen fue una dictadura, pues tuvo presos, perseguidos o deportados a los miembros de la oposición.

Las elecciones de 1956 permitieron la aparición de nuevas fuerzas políticas que iban a tener más tarde un desarrollo espectacular, pero representó al mismo tiempo el retorno, por segunda vez, de Manuel Prado a la Presidencia de la República. Su período transcurrió apaciblemente y desarrolló la labor rutinaria que tiene todo gobierno, pero lo más importante es que instauró un perfecto ambiente de convivencia política, que permitió el libre desarrollo de la prensa y de los partidos políticos, tanto de los que apoyaban al régimen, como de los que se encontraban en la oposición. A diferencia de su primer gobierno, en el cual Prado fue más bien un dictador encubierto, en el segundo existió un ambiente democrático, y preparó a la ciudadanía para mejores logros. Prado significó además el retorno a las libertades políticas, que se habían oscurecido después de 1948, así como la derogación de las leyes de emergencia que habían afectado la normalidad institucional y política del país desde 1932 (con la excepción del trienio 19451948).

El 18 de julio de 1962, faltando escasos diez días para que Manuel Prado culmine su período, es derrocado por el Comando Conjunto de las Fuerzas Armadas, inaugurando así un nuevo tipo de militarismo. En realidad, el golpe de Estado fue dado no contra Prado, que terminaba su período, sino contra la posible elección de Haya de la Torre a la Presidencia de la República (una tradicional disputa del Apra con el Ejército arrancó en 1932, y sólo desaparecería definitivamente en 1979, con la muerte de Haya de la Torre, fundador y líder de ese partido). La Junta Militar de Gobierno, verdaderamente institucional, se queda en el poder tan sólo un año y 
convoca a elecciones en 1963. Este año es elegido Presidente Fernando Belaunde Terry, quien debió terminar su período en 1969, pero cae derrocado en 1968. Su administración se caracteriza por haber ejecutado o iniciado grandes obras de infraestructura con sentido de futuro; así la denominada Carretera Marginal de la Selva, y un vasto plan de viviendas, puentes, carreteras y escuelas. Desde el punto de vista político, continuó la huella de Prado, ahondándola y con mucho mayor mérito, pues por el cambio del sistema electoral y la alianza de sus adversarios, se quedó sin mayoría en el Congreso, lo cual debilitó enormemente su gobierno. Sentó las bases del futuro Estado-empresario, e incluso de la solución que luego se dio a la controversia con la International Petroleum Company (IPC) así como la reforma agraria, que fue matizada en el parlamento por la oposición (Apra y Odriísmo). En todo caso, la excesiva fragilidad del gobierno lo hizo tan vulnerable, que un golpe de Estado presidido por el general Juan Velaśco Alvarado, le puso término el 3 de,octubre de 1968.

E1 gobierno militar de 1968 se presentó desde un principio como revolucionario e hizo vastas obras que lo pueden calificar como tal. Algunas de ellas son: i) reestructuración del aparato del Estado; ii) continuación y profundización de la reforma agraria; iii) creación del Estado empresario, reservándose para sí importantes sectores en exclusividad, como es el caso de los servicios de luz, la explotación del petróleo, etc.; iv) reestructuración de la comunidad indígena en la sierra; v) reestructuración del régimen de propiedad en la actividad manufacturera; vi) rediseño de la política exterior del Estado, en reemplazo de la que imperaba desde fines del siglo pasado, que fue montada para defender las cuestiones limitrofes no saldadas; vii) reestructuración del régimen educativo. Estas y otras reformas atraviesan y condicionan todo el período militar que va desde 1968 hasta 1980, aún cuando a partir de 1975, tales enfoques quedan matizados, disminuidos o redimensionados, con la llegada al poder del general Francisco Morales Bermúdez, que derroca al general Velasco, acusado de autoritarismo y personalismo. Entre los aspectos francamente censurables de este largo período, deben señalarse fundamentalmente dos: haber eliminado la democracia política que vivía el país y haber suprimido toda forma de libertad de expresión, lo cual culminó 
con la incautación de los diarios de circulación nacional en julio de 1974, devueltos a sus propietarios tan sólo en julio de 1980, cuando volvió el país al régimen constitucional.

Desde un punto de vista institucional y político, el gobierno militar es simplemente una dictadura: clausura diarios, hasta que los confisca a todos; apresa, deporta a la oposición; persigue todo conato opositor. Pero por otro lado, al iniciar grandes cambios despierta simpatías en diversos sectores, y ellos, sin lugar a dudas, quedarán, aún cuando hayan sido reformulados o replanteados. El gobierno militar se enfrenta con la oposición y sobre todo a una crisis muy seria, iniciada en 1973 con la crisis energética, y que sumada a la deuda externa, agobia al país desde entonces. Es importante también esta etapa, porque en julio de 1977 se convocan elecciones para una Asamblea Constituyente, que se instala el 28 de julio de 1978, y que durará en funciones exactamente un año. La nueva Constitución es aprobada y sancionada en 1979; pero sólo entrará en vigor en 1980, cuando se instala el nuevo gobierno constitucional, por un período de cinco años, presidido por Fernando Belaunde Terry, esta vez en su segunda administración.

La instauración del nuevo régimen en 1980 significó varios aspectos positivos; el primero de ellos devolver a sus legítimos propietarios los medios de expresión escrita, después de seis largos años de dictadura y mordaza, lo que es continuado por el libre juego de las instituciones, tanto públicas como privadas. A diferencia de su primera administración en que el programa reformista de Belaunde es enervado por una mayoría (el Partido Aprista más la Unión Nacional Odrísta); en esta oportunidad el gobierno tiene mayoría en las Cámaras, motivo por el cual no hay bloqueos que frenen el desarrollo del régimen. Pero si bien con mayoría parlamentaria el gobierno se esmera en ser un gobierno de transición, sin hacer nada nuevo ni espectacular. Continúan las obras de orden eléctrico, sanitario, la construcción de escuelas, puen tes, carreteras, etc. dentro de un tono moderado y respetuoso del orden jurídico. Sin embargo, asoman dos problemas que hasta ahora afligen al país: la subversión desatada por el grupo terrorista, escindido del Partido Comunista, conocido simplemente como "Sendero Luminoso", y la seria crisis económica, tanto interna 
como externa, que lleva a una parálisis de la economía, y posteriormente a una situación delicada con los acreedores extranjeros, que se agudizará a partir de 1985 .

El período de cinco años (1980-1985) lo culmina Belaunde satisfactoriamente. Las elecciones generales son convocadas a fines de 1984, y se llevan a cabo en el mes de abril de 1985. Pero sucede lo previsto: ninguno de los candidatos ha alcanzado más de la mitad de los votos, y es necesario recurrir, en principio, a la segunda vuelta, institución novísima prevista en la Constitución de 1979. Tras un agitado debate, la segunda fuerza política, Izquierda Unida (IU) con su candidato Alfonso Barrantes Lingán, declina participar en una segunda elección, y el Jurado Nacional de Elecciones proclama a Alan García Pérez, candidato del Partido Aprista, como ganador de la contienda, y por un período de cinco años (19851990).

El nuevo gobierno aprista, llegado al poder después de más de cincuenta años de participación en la vida política del país, trajo nuevos ímpetus. Se mostró decidido a combatir la acción subversiva, a dar un sentido de autoridad al aparato del Estado, a frenar la inflación y a promover el desarrollo interno, a limitar el pago de la deuda externa al $10 \%$ de las exportaciones y a inaugurar una nueva política exterior acercándose a los pueblos del Tercer Mundo, lo que incluye un apoyo al régimen sandinista. Igualmente agiliza los pasos para poner en ejecución el proceso de regionalización previsto en la Constitución y a favorecer a las zonas más deprimidas del país, calificadas a partir de entonces con el nombre algo caprichoso de "trapecio andino". Este empeño dio sus frutos; en dos años ha crecido el producto bruto interno, las libertades públicas se han mantenido, pero en el gobierno se ha acentuado la tendencia a copar los principales puestos y departamentos públicos, con la idea de que el partido gobernante maneje el aparato del Estado sin interferencias y a veces con excesos (matanza en los penales en junio de 1986). A fines de 1986, se inicia una campaña, promovida desde el poder, para modificar la Constitución y permitir la reelección inmediata, que a la postre fracasó. Los primeros dos años de gobierno encierran una gestión exitosa a nivel de manejo de la economía interna, aumentando la deman- 
da, pero sin ninguna garantía de que esta reactivación económica tenga larga duración. En mayo de 1987 el modelo da síntomas de deterioro. En las actuales circunstancias el panorama todavía es promisorio, aún cuando el futuro no deja de despertar incógnitas, que el tiempo se encargará de despejar (1).

\section{Algunos problemas y algunas situaciones no resueltas}

Haciendo un balance de lo que ha sucedido en la presente centuria, podemos extraer una conclusión general a nivel político: el sistema que funcionó a nivel de elites en el siglo pasado y que así continuó hasta 1919, ha visto aparecer los grandes partidos que a su vez representan la inserción de las masas en la vida política del país. Por un lado, los problemas han aumentado, pero por otro ha habido mejoras sensibles. Se ha ensanchado el nivel de productores y consumidores, los órganos constitucionales funcionan con mayor regularidad y consistencia. El sistema electoral empezó una nueva etapa en 1931, después de varias décadas de procesos impuros, y se sentaron entonces bases duraderas, que lamentablemente tuvieron un eclipse largo, que llega, en términos generales hasta 1956. Desde este año existe una mayor pureza electoral y desde 1963 no hay un solo proceso que haya podido ser calificado como fraudulento o vicioso.

E1 movimiento sindical, campesino, gremial, ha aumentado su participación en la vida del país. Ha sido extendida la red de comunicaciones; el país se ha modernizado, como lo demuestran los medios masivos de comunicación, la marea creciente de industrias manufactureras y el auge de las exportaciones no tradicionales; el aumento de la producción y la productividad, y también una mayor intensidad de la vida cultural. Por cierto, todo esto no es un desarrollo lineal, sino con altas y bajas. De hecho, en algunos sectores hay un franco retroceso, pero en términos generales se ha adelantado, lo cual no significa que todos los problemas hayan sido resueltos. Finalmente, hay que mencionar que el afianzamiento

(1) Téngase presente que este trabajo alcanza sólo hasta 1987, en razón del homenaje al cual está destinado. 
constitucional, ha traido dos aspectos importantes: el respeto a la legitimidad constitucional y el alejamiento del fantasma "golpista". Esto se comprueba en dos hechos recientes: la reorganización de las Fuerzas Policiales, y su unificación paulatina en una sola (Policía Nacional), y la creación del Ministerio de Defensa (abril de 1987), en lugar de los tres ministerios existentes durante años. Ambas medidas se han llevado a cabo públicamente, con grandes debates, pero sin erosionar el sistema.

\section{Las tres constituciones del presente siglo}

Hemos ya adelantado que el siglo se inicia con la Carta de 1860 , la cual fue reemplazada por la de 1920. Pero en rigor, ka Carta de 1920 no era necesaria. Como veremos más adelạnte, y salvo algunas modificaciones menores, la Constitución de 1860 casi no difiere de la de 1920, por lo que no puede menos que concluirse que la de 1920 no era imprescindible. Esta última fue promulgada en forma ad-hoc por el nuevo gobierno del señor Augusto B. Leguía, quien permaneció dictatorialmente en el poder durante once años. Cuando cae derrocado en 1930. su Constitución sigue igual suerte. En consecuencia, se discutirá y aprobará una nueva Constitución, la de 1933. Si analizamos este texto y lo comparamos con el de 1920 , vemos también muy pocas diferencias, y cabría preguntarse si valía la pena desde el punto de vista formal sustituir la Carta de 1920 por la de 1933. Pero lo que no era lógico desde un punto de vista jurídico, si lo era desde una lógica de la política. Tuvo que darse pues una Constitución, que en sí misma era innecesaria, pero que políticamente sí lo era. Por fin adviene la vigente Constitución de 1979, que rompe todos los esquemas previos, tanto a nivel de Estado como de regulaciones, procesos y garantías. Si bien recoge en esencia lo más positivo e importante de la tradición política del Perú, en otros puntos es totalmente innovadora. Esta Constitución es pues, en cierto sentido, tradición, y en otro, ruptura. Es en rigor, en este siglo, la única Constitución verdaderamente necesaria, innovadora y representativa de las necesidades del país. Es de esperar que sea también la última de esta centuria. 


\section{La Constitución de 1920}

El 4 de julio de 1919 se instala el gobierno provisional de Augusto B. Leguía, llegado al poder mediante un golpe de Estado civil, apoyado por elementos castrenses. Acto seguido convoca a una Asamblea Nacional para reformar la Constitución (de 1860). En forma paralela, somete a la ciudadanía mediante plebiscito, 19 puntos para una reforma constitucional. Tales puntos eran los siguientes:

i) La renovación del Poder Legislativo será total y coincidirá necesariamente con la renovación del Poder Ejecutivo. El mandato de ambos poderes durará cinco años.

ii) E1 Poder Legislativo constará de un Senado compuesto de 35 senadores y de una Cámara compuesta por $110 \mathrm{di}-$ putados, cifra que no podrá modificarse sino por expresa reforma constitucional.

iii) Los senadores y diputados serán elegidos por voto popular directo.

iv) El Congreso ordinario funcionará cuando menos noventa días al año y ciento veinte cuando más.

v) Las Cámaras se reunirán únicamente para instalar sus sesiones, sancionar los tratados internacionales, y cumplir las atribuciones electorales que la Constitución asigna al Congreso.

vi) Hay incompatibilidad entre el mandato legislativo y todo empleo público.

vii) Los ministros diplomáticos serán nombrados por el Gobierno, con aprobación del Senado.

viii) Las garantías individuales no podrán ser suspendidas por ninguna ley ni por ninguna autoridad. 
ix ) Los nombramientos judiciales de primera y segunda instancia, serán ratificados por la Corte Suprema, cada cinco años.

x) La contribución sobre la renta será progresiva.

xi) Los conflictos entre el capital y el trabajo serán sometidos al arbitraje obligatorio del Estado.

xii) El Congreso no podrá otorgar gracias personales ni aumentar el sueldo de los funcionarios públicos, sino por iniciativa del Gobierno.

xiii) No podrá crearse moneda fiduciaria de curso forzoso, salvo en el caso de guerra nacional.

xiv) Habrá tres legislaturas regionales, al norte, centro y sur de la República, con diputados elegidos por las provincias al mismo tiempo que los representantes nacionales. Estas legislaturas tendrán todos los años una sesión que durará treinta días improrrogables. Sus resoluciones serán comunicadas al Poder Ejecutivo para su cumplimiento.

xv) Los concejos provinciales son autónomos en el manejo de los intereses que les están confiados.

xvi) Habrá un Consejo de Estado compuesto por seis miembros.

xvii) Sólo el gobierno podrá conceder, conforme a ley, pensiones de jubilación, cesantía y montepío.

xviii) Nadie podrá gozar más de un sueldo o emolumento del Estado.

xix) El próximo Congreso se instalará el 15 de setiembre de este año (1919) presidido por el Presidente del Senado y funcionará durante treinta días como Asamblea $\mathrm{Na}$ - 
cional para promulgar las reformas que resulten aprobadas por el voto plebiscitario.

Estos puntos fueron analizados por una Comisión presidida por Javier Prado, quien propuso un tex to reformado de la Constitución de 1860 , al cual se habían insertado diversas normas y de manera especial los puntos sancionados plebiscitariamente. Tal proyecto fue remitido a la Asamblea Nacional, en donde ocasionó un serio impasse. Mientras que unos sostenían la necesidad de reformar la Constitución de acuerdo al mandato popular, otros argumentaban que había que hacer una Constitución nueva, que recogiese esos y otros puntos más. En los ardorosos debates de esos días, se afirmó que la Asamblea no tenía poderes constituyentes, o que si los tenía eran sólo para introducir las reformas votadas popularmente, pero no para ir a una nueva Constitución. El nuevo gobierno sin embargo, que representaba una fuerza distinta a las fuerzas en pugna, quiso distinguirse por dar una nueva Constitución, y eso lo consiguió a través de sus partidarios en las cámaras. Tras largos debates, se arribó a la conclusión de que el plebiscito era "irrevocable", esto es, no podía dejarse de lado, pero no era "intangible". Fruto de ello fue la sanción de la nueva Constitución Política del Estado, que más tarde promulgó el Presidente Leguía el 18 de enero de 1920.

¿Cuáles son las características de la Constitución de 1920? Desde un punto de vista formal es un texto sobrio, bien construido, con 161 artículos. Su división es la siguiente: diecinueve títulos dedicados a: i) la Nación y el Estado; ii) garantías nacionales, iii) garantías individuales; iv) garantías sociales, v) de los peruanos, vi) de la ciudadanía y del derecho y garantías electorales, vii) de la forma de gobierno, viii) del Poder Legislativo, ix) de las Cámaras Legislativas, $\mathrm{x}$ ) de la formación y promulgación de las leyes, xi) Poder Ejecutivo, xii) de los Ministros de Estado, xiii) del Consejo de Estado, xiv) del régimen interior de la República, xv) Congresos Regionales, xvi) Administración Municipal, xvii) Fuerza Pública, xviii) Poder Judicial y xix) Disposiciones Transitorias.

Salvo una mejor sistemática (por ejemplo haber distinguido por vez primera las garantías individuales de las garantías sociales) 
la Carta en mucho se asemeja a la anterior Constitución de 1860, como lo ha demostrado en un conocido paralelo Manuel Vicente Villarán y otras voces autorizadas. Con todo, hubo algunas diferencias que son:

a) La contribución progresiva sobre la renta,

b) Prohibición de gozar más de un sueldo o emolumento por parte del Estado,

c) Libertad de creencia y de conciencia,

d) Consagración constitucional del Habeas Corpus,

e) Reconocimiento de las Comunidades Indígenas e intangibilidad de sus tierras,

f) Incorporación de la cláusula Calvo,

g) Consagración del derecho a las nacionalizaciones por parte del Estado, para tomar a su cargo bienes o servicios.

h) Proteccionismo laboral y arbitraje estatal en los conflictos entre el capital y el trabajo,

i) Prohibición de monopolios,

j) Voto popular directo,

k) Fijación del período gubernamental en 5 años,

1) Ratificación de los magistrados por la Corte Suprema cada cinco años, $y$

m) Congresos regionales (afán descentralista).

Lo anterior demuestra cuales fueron las principales novedades del tex to de 1920, en relación con el que lo precedió de 1860, y además que en sus lineamientos generales no tuvo mayores innovaciones, aun cuando tímidamente apuntó un cierto interés social y una actitud interventora del Estado, no sólo por razones de interés general sino de protección a los sectores menos favorecidos de la 
sociedad. Tuvo mayor sensibilidad social que los tex tos constitucionales anteriores, tributo obligado a las inquietudes de la época.

Lo que pasó con esta Constitución, que tuvo poquísimas modificaciones durante el tiempo de su vigencia, es que no fue respetada ni por sus propios autores. Es sabido que las sucesivas reelecciones del Presidente Leguía y sus principales colaboradores; el silenciamiento de la opinión pública y la obsecuencia del Poder Judicial que no protegía a los ciudadanos que interponían recursos de habeas corpus contra excesos del poder central, el continuo divorcio entre lo escrito y lo vivido, el mentís político de una norma tan continuamente violada, hizo que ésta cayese en total descrédito, si bien muchos de sus asertos se recogieron en la siguiente Constitución de 1933, y otros permanecen hasta ahora o han vuelto a tomarse en cuenta. Fue, en conclusión, un hermoso experimento de laboratorio, que no pudo ser aplicado al organismo político y social, como hubiera sido deseable.

\section{La Constitución de 1933}

Producida la defenestración de Leguía, esto trajo, como ha sido señalado, la caída de su Constitución, la de 1920. Largos y desordenados meses siguieron a este derrocamiento, hasta que en 1931 fueron convocadas, simultáneamente elecciones presidenciales y de Congreso Constituyente, con funciones tanto legislativas como constituyentes. El Congreso se instaló oficialmente en diciembre de 1931 con un Poder Ejecutivo presidido por el teniente coronel Luis M. Sánchez Cerro. Los debates parlamentarios fueron mezclados - sobre todo durante el año de 1932 - con otros asuntos de carácter nacional e internacional, y el tex to fue finalmente promulgado en abril de 1933.

Los debates se iniciaron, como dijimos, en diciembre de 1931 y tuvieron como referencia el anteproyecto preparado por la comisión presidida por Manuel Vicente Villarán, que presentó una extensa exposición de motivos y un anteproyecto que lamentablemente no fue tenido en cuenta por los convencionales. Si bien es cierto que en 1920 existió también una comisión ad-hoc presidida por Javier Prado, el documento emanado por la comisión presidida 
por Villarán, es el documento constitucional más importante de este siglo, pues encierra no sólo sabias lecciones de prudencia e historia política, sino de asertos y recomendaciones que todavía hoy pueden ser leídas con provecho. Ellas también influenciaron en los debates de la década de 1970, cuando una reforma constitucional fue anunciada y dio como fruto la vigente Carta de 1979.

Entre otros aspectos que vale la pena destacar en este período, hay que mencionar que a diferencia de la Asamblea Nacional de 1919, fue el de 1931 un Congreso movido, con continuas tensiones y fricciones, que vivió un ambiente nacional e internacional caldeado, que contó en su seno con una oposición alerta y denodada que emprendió una lucha sin cuartel contra la mayoría gobiernista que dominaba la Asamblea, y que además se cometieron gruesos excesos que sin lugar a dudas empañaron la labor constituyente. Entre los excesos que vale la pena mencionar, el más grave consiste en haber mutilado el Congreso, cuando el propio gobierno irrumpió en el recinto parlamentario (febrero de 1932) y defenestró a 27 de sus miembros, la mayoría de los cuales pertenecía a las filas del Partido Aprista, con lo cual aplicó un desafuero de facto que la Asamblea convalidó a posteriori, en forma por demás vergonzosa.

Otro aspecto que es importante en este Congreso fue la presencia de representantes de partidos de masas, con una ideología altamente radical. Así, al lado de los socialistas y los descentralistas que representaban fuerzas nuevas, y un grupo menor de independientes, existía un quinto de la asamblea compuesta por el Partido Aprista, que es el primer gran partido de masas que aparece en nuestra historia republicana, y que adicionalmente en aquel entonces estaba afiliado a una filosof ía marxista, si bien atemperada por perspectivas iberoamericanas que eran reclamadas por la realidad. Es importante destacar además que en su momento fue una asamblea plural y polémica, a despecho de la anterior de 1919 que fue monocorde y que discurrió sin mayores enfrentamientos. Como cosa curiosa vale la pena anotar que en medio de tanto pacifismo y talento, la Carta de 1920 no tuvo prácticamente vida efectiva, ni siquiera para sus propios autores, a diferencia de la de 1933, con larga vida, tanto formal como efectiva, y que sólo sería 
reemplazada, en su totalidad, en 1980, es decir, casi cincuenta años después. Claro está que al lado de la vigencia formal hay que señalar las largas "vacaciones" a la que la sometieron los diversos regímenes dictatoriales que se sucedieron en tan dilatado lapso, pero lo cierto es que existen también períodos en los cuales funcionó regularmente, como lo fue el de Bustamante (1945-1948), el segundo período de Prado (1956-1962) y el primer período de Belaunde (1963-1968). Por paradójico que parezca, debemos señalar que hasta el momento y en este siglo, la Carta de 1933 es la que más experiencia y efectividad ha tenido hasta ahora, pero esperamos que sea superada en el futuro por el vigente texto de 1979.

Formalmente el texto de 1933 es más extenso que el de 1920, como el de 1979 lo es más que el de 1933, como si existiese, con el transcurso del tiempo una tendencia a promulgar textos cada vez más frondosos. La Carta del 33 tiene en total 236 artículos y nueve disposiciones transitorias. En su larga vida formal tuvo muy pocas reformas y todas ellas de mínima importancia, salvo la que fue realizada en 1964 para permitir la reforma agraria, como veremos más adelante.

E1 texto está repartido en 236 artículos, como ya ha sido señalado, y distribuido a su vez en 16 títulos, que son los siguientes: i) Estado, territorio y nacionalidad, ii) garantías constitucionales (nacionales, sociales e individuales), iii) educación, iv) ciudadanfa y sufragio, v) Poder Legislativo, vi) formación y promulgación de las leyes, vii) Poder Ejecutivo (incluye Presidente de la República, ministros de Estado, comisiones consultivas y consejos técnicos), viii) Consejo de Economía Nacional, ix) régimen interior de la República, x) administración departamental y municipal, Concejos Departamentales, Concejos Municipales, xi) Comunidades de Indigenas, xii) Fuerza Armada, xiii) Poder Judicial, xiv) Religión, xv) Reforma de la Constitución; y xvi) Disposiciones transitorias.

Los grandes temas objeto de agudas polémicas en el seno de la constituyente fueron, entre otros, el voto de los analfabetos y el de las mujeres (que fue admitido sólo para las elecciones municipales); las atribuciones del Congreso y del Presidente de la Re- 
pública (que fueron remodeladas, creando una gran fuerza en el parlamento, que permitió pensar en un régimen semi-plarlamentario entre nosotros, y que en la práctica tuvo efectos lamentables); la composición del Poder Legislativo, que consagró la existencia de una.cámara (el Senado Funcional) con composición corporativa, muy a tono con las tendencias dominantes en aquel entonces, pero que nunca llegó a instalarse; la consagración teórica del Estado descentralizado con la instauración de los Concejos Departamentales (que nunca funcionaron) y los Concejos Municipales (que sólo en 1963 fueron elegidos por el voto directo); el problema del veto presidencial (que fue eliminado aun cuando usado en la práctica de todo el período); la sanción y proscripción de todos los partidos de organización internacional (que fue aplicado durante años, para perseguir al Partido Comunista y al Partido Aprista, lo que se hizo, con variantes, hasta 1962).

En comparación con el texto de 1920 , el de 1933 contiene indudables novedades (como el de la descentralización, o el mayor perfeccionamiento de las entonces llamadas garantías sociales), pero en sustancia sigue las huellas de la Carta anterior, sin aportar nada sustantivo, y siendo además, desde un punto de vista de estructura formal; inferior a la que la precedió.

La reforma más importante que sufrió la Carta de 1933, fue en 1964, y que aquí debe ser recordada por su trascendencia. El problema era el siguiente: dentro del gran proceso de renovación de las conciencias y del inquieto marco social de la década del sesenta -que es común a toda la América Latina- el gobierno recién llegado al poder en 1963, envió al Congreso un proyecto de reforma agraria, que buscaba, entre otros puntos, expropiar tierras para darlas a los campesinos que carecían de ellas. Pero la Constitución en su artículo 29, al igual que todas las anteriores, había establecido la inviolabilidad del derecho de propiedad y que la expropiación sólo podía darse mediando previo pago de su valor justipreciado. Esto chocaba con el proyecto de ley que establecía el pago en armadas anuales de larga redención (que por lo demás era la única manera de hacerlo). El gran debate que vivió el país en el período 1963-1964, entre los llamados por la opinión pública "los barones de la tierra", y las organizaciones 
populares y el partido de gobierno, demostró por vez primera no sólo la libre actuación de los grupos de poder en relación con un trascendental paso histórico, sino cómo una Carta podía oponerse a una reforma social largamente sentida y auspiciada por la colectividad. Todo ello llevó, por la propia dinámica del régimen constitucional, a la reforma consecuente, de manera tal que a partir de aquel momento se permitió, y para muy contados casos (guerra, remodelación de poblaciones y reforma agraria) la expropiación con pago diferido. Este importantísimo precepto incorporado en 1964 a la Carta de 1933, y que perfeccionado, ha sido repetido en la vigente Carta de 1979, representó, desde el punto de vista constitucional, quizá la más audaz reforma que se había realizado hasta ese momento en el presente siglo.

En conjunto, la Constitución de 1933, nacida en medio de tantas fragilidades, acicateadà por presiones externas e internas, vapuleada por varios golpes de Estado y leyes de emergencia, cubrió, sin quererlo, un largo período que ha sido un laboratorio viviente de lo más interesante de la política y del proceso constitucional en lo que va del siglo.

\section{La Constitución de 1979}

En 1968 se dio un nuevo golpe de Estado en el país; en esta oportunidad no era un golpe más o un golpe menos; tampoco la expresión monda y lironda de la ambición de un caudillo. Se trataba de un golpe institucional de las Fuerzas Armadas, jefaturadas por el general Juan Velasco Alvarado, que estaba decidido a dar la batalla por las grandes reformas sociales anunciadas desde 1963 por el régimen de Belaunde, pero que el Apra, aliada con el odriísmo, bloqueó desde el Parlamento. En un momento, parece que el movimiento insurreccional fue parcial y sólo del Ejército, pero al final, por acción $\mathrm{u}$ omisión, las demás fuerzas se plegaron. Comienza así un largo período militar, el más largo de nuestra historia, que dura doce años, y que culminará en julio de 1980. El gobierno militar conoce dos etapas, la primera es de 1968-1975; presidida por el general Velasco que se caracteriza por cambios estructurales muy radicales, presencia del Estado en la economía de manera sobresaliente, agresiva política exterior, pero también errores econó- 
micos e intransigencia con la oposición; la segunda se inicia en 1975 y culmina en 1980. Pretende reordenar las reformas, matizar algunas de ellas, y preparar la transferencia del poder a los civiles en 1980, previa convocatoria a una Asamblea Constituyente. Esta se instala el 28 de julio de 1978 y finaliza sus sesiones el 13 de julio de 1979. Un año después, en julio de 1980, se restaura la normalidad constitucional, que continúa hasta la fecha.

Las características que tiene esta Asamblea, y que la distinguen de las anteriores, son las siguientes: i) goza del plazo de un año para discutir y aprobar el nuevo texto, a diferencia de los brevísimos períodos que gozaron constituyentes anteriores; ii) actúa junto a un gobierno de facto que le es ajeno y hasta hostil, el cual empero, respeta sus decisiones; esto contrasta con asambleas anteriores, que actuaron conjuntamente con un régimen constitucional o constitucionalizado, iii) no cuenta, a diferencia de otras constituciones, con un anteproyecto con el cual trabajar y que oriente sus labores, lo cual explica la falta de tecnicismo, las redundancias, lagunas e incorrecciones que tiene el texto, no obstante sus aspectos positivos, iv) tuvo tras de sí una larguísima y agitada experiencia politica que le servirá para extraer del pasado lo mejor de sus experiencias políticas; v) fue una Asamblea que sólo tuvo actividades constituyentes y no legislativas, a diferencia de lo que sucedió en anteriores ocasiones y en otros países; vi) no existieron representantes del poder constifuido en aquel momento (los militares), como sí sucedió, por ejemplo, en la España de 1978; vii) se rebajó la edad del voto a los 18 años, pero se negó la participación del analfabeto, que consagró meses después la nueva Constitución, viii) la dación de una nueva Constitución fue la conditio sine qua non para la convocatoria a las elecciones generales en 1980; es decir, era el camino obligado para llegar a ellas, impuesto por el gobierno militar y que a la larga, todos aceptaron, ix ) a diferencia de lo sucedido en anteriores oportunidades, hubo esta vez total y absoluta participación de todos los segmentos ideológicos del mapa electoral (aún cuando se abstuvo un partido político, Acción Popular, cuya ideología sin embargo estuvo defendida en el interior de la Asamblea por otros grupos afines); $x$ ) a diferencia de lo que sucedió en épocas anteriores, todos sus miembros, sin excepción, fueron respetados durante el año que duraron sus labores; 
xi) ninguna de las fuerzas políticas actuantes tuvo, sobre un total de 100 representantes, más del 50\% de sus miembros; esto hizo indispensable el entendimiento y las mutuas concesiones entre ellas (así, el texto actual es realmente plural y amplio, toda vez que fue fruto de un consenso entre sus miembros, consenso que no lo fue de las ideas sino de los intereses, ya que todos eran concientes de que sin la Constitución lista en un año, no habría elecciones y la dictadura continuaria).

Desde el punto de vista formal, la Carta de 1979 se aparta de todas las anteriores por dos notas: su excesiva extensión y su afán reglamentarista. Son exactamente 307 artículos y dieciocho disposiciones generales y transitorias (dedicadas sobre todo a fijar pautas sobre la transferencia del poder a los civiles, que estaba of recida para 1980, y que en sus lineamientos generales fue respetada).

Hay que llamar la atención sobre el aspecto externo de este texto, pues a diferencia de las cartas anteriores que consagraron expresa y concretamente dos partes marcadas, una dogmática y otra orgánica, la actual tiene una tercera parte, que podemos llamar por comodidad la parte económica o constitución económica, en donde aparecen sendos capítulos dedicados a la propiedad, a la banca, a la reforma agraria, a la utilización de los recursos naturales, entre otros tópicos.

Su esquema es el siguiente: i) derechos y deberes fundamentales de la persona (que incluye la persona, la familia, la seguridad social, la salud y el bienestar, la educación, la ciencia y la cultura, el trabajo, la función pública, los derechos políticos, los deberes), ii) el Estado y la Nación (la nacionalidad, el territorio, la integración, los tratados), iii) el régimen económico (los recursos naturales, la propiedad, la empresa, la hacienda pública, la moneda y la banca, el régimen agrario, las comunidades campesinas y nativas); iv) la estructura del Estado (Poder Legislativo, la función legislativa, la formación y promulgación de las leyes, el presupuesto y la cuenta general, el Poder Ejecutivo, el Consejo de Ministros, el régimen de excepción, el Poder Judicial, el Consejo Nacional de la Magistratura, el Ministerio Público, la descentralización, gobiernos 
locales y regionales, la defensa nacional y del orden interno, el Jurado Nacional de Elecciones); v) las Garantías Constitucionales; vi) la reforma de la Constitución; vii) disposición final, y viii) disposiciones generales y transitorias.

Las principales innovaciones que consagra este tex to son los siguientes: i) amplísimo respaldo y reconocimiento a los derechos humanos en todas sus gamas, lo que fue posible no sólo como respuesta a los excesos de la dictadura que entonces se vivía, sino por el ambiente internacional a favor de los derechos humanos, ii) introducción o ratificación de un conjunto de mecanismos procesales para la defensa de la persona y del sistema democrático, como son el Habeas Corpus, el Amparo, la Acción Popular, y la Acción de Inconstitucionalidad, iii) consagración de un explícito sistema económico del Estado, que se caracteriza por su flexibilidad, pluralismo y economía de mercado, a la cual sin embargo se califica de "social", lo que dará que pensar que estamos frente a un "liberalismo social", iv) introducción de nuevos órganos constitucionales, con plena y total autonomía, que participan en las más altas funciones del Estado (como es el caso del Tribunal de Garantías Constitucionales, el Consejo Nacional de la Magistratura, el Ministerio Público (a cuyo frente se encuentra el Fiscal de la Nación), el Jurado Nacional de Elecciones (existente desde 1931), etc.), v) reconocimiento de la jurisdicción supranacional para la def́ensa de los derechos humanos, y expreso reconocimiento de la competencia de la Corte Interamericana de Derechos Humanos, vi) redefinición de la estructura del Estado peruano, con la diferenciación de la composición del'Parlamento, en el cual el Senado será representativo tan sólo de las regiones, y al cual se confían además funciones no políticas, que sí tiene la Cámara de Diputados; vii) consagración de un modelo regional, que todavía no ha sido implementado, pero que se encuentra en proceso; viii) separación amistosa con la Iglesia Católica, siguiendo los lineamientos de un nuevo acuerdo con la Santa Sede, que significa la superación del patronato clásico que tuvieron nuestras repúblicas, hasta bien avanzada la mitad del siglo; ix) refuerza la investidura del Jefe del Estado creando un gobierno con una marcada tendencia presidencial, que supera el enfoque semi-parlamentario de la Carta de 1933, y, x) se elimina la capacidad y la iniciativa del Parlamento para generar el gas- 
to público (que fue siempre motivo de déficits presupuestales en las últimas décadas).

Esta Constitución, como fácilmente puede verse, rompe toda una tradición e inaugura una nueva. Recoge de lo antiguo lo más valioso, crea mecanismos para resolver conflictos y evitar que se repitan las experiencias negativas del pasado; y a su vez, siendo amplia y generosa en sus enunciados, se proyecta con fïmeza hacia el siglo XXI, como lo quiso Haya de la Torre, en el discurso inaugural que leyó el 28 de julio de 1978, en su calidad de Presidente de la Asamblea Constituyente.

Sancionada la Carta en 1979, fue remitida al Poder Ejecutivo de facto, presumiblemente con fines de publicidad. La Asamblea había sostenido que ella misma había promulgado la Constitución, motivo por el cual no se explica porque la envió al Ejecutivo. En todo caso, el gobernante de facto la devolvió con observaciones, que son rechazadas por la Asamblea en pleno, el 13 de julio de 1979. Las observaciones del gobierno estaban referidas no al contenido de la Carta, que en rigor no le compete, sino a un aspecto procesal que sí le interesa: no puede admitir lo que ha hecho la Asamblea, o sea, establecer que ciertos artículos constitucionales entren en vigencia de inmediato, cuando el compromiso es que la Carta entre en vigencia recién en 1980, con la restauración del orden constitucional. Lo cierto es que la Asamblea rechaza el veto del Ejecutivo, y se disuelve. Promulgada o no (más no que sí), lo cierto es que la Constitución durante todo un año no es publicada oficialmente ni observada en cuanto tal. Meses después, se convocan elecciones generales, y es elegido por amplia mayoría Fernando Belaunde Terry, que esta vez vuelve al poder con mayoría en las cámaras. La misma noche del 28 de julio de 1980, el Presidente Belaunde pone el cúmplase a la Constitución y ordena su publicación oficial, lo que efectivamente sucede.

Desde entonces, han pasado algunos, pocos años. La Cor:stiturión ha sido puesta a prueba; se han reglamentado varios de sus apartados, se han instalado varias de las instituciones por ella creadas.. En términos generales, el nuevo tex to funciona, es respetado. Aun más, se han notado algunos de sus vacíos y deficiencias y se 
han propuesto varias reformas que en todo caso deben ser sopesadas y analizadas con calma. Mientras tanto, el país discurre por su vida institucional con los sobresaltos y tropiezos propios de nuestras repúblicas.

\section{Recapitulación y consideraciones conclusivas}

El nuevo siglo se inició en nuestro país sin estridencias. Por un lado, un juego tradicional reducido en la práctica a un solo partido, el Partido Civil, fundado en 1872, y de tanta gravitación desde esa época, hasta mediados de 1930. Todos o casi todos los Presidentes desde aquel año, pertenecieron al Partido Civil, o simpatizaron con él, o en todo caso, tuvieron que aceptar sus condiciones. Piérola (1895-1899), el más destacado gobernante de ese período, tuvo que someter a su partido, el Demócrata, a una alianza con el Partido Civil. El mundo avanza, decían los optimistas, y ésto se reflejaba en el quehacer de todos los días. En lo normativo, el Estado seguía siendo el Gendarme necesario y el gobierno era bueno porque casi no gobernaba. En lo social, existía una pequeña minoría dirigente y una gran masa de población que vivía al margen del sistema formal; al medio, una finísima capa, muy delgada, de elementos mesocráticos, que pugnaban por subir o a veces por no descender. La fiebre del caucho y del progreso, invadía todos los ámbitos. En el orden constitucional, y salvo una ligera quiebra en 1914 , que se resolvió en pocos meses, hubo continuidad constitucional, y toda auguraba que así seguirían las cosas.

El siglo XIX, para nosotros, acabó en realidad en 1919. La belle époque se esfumó. Los nuevos vientos los trajo Leguía, quien reflejó y a su vez encarnó los cambios que venían o que eran necesarios. Su ingreso representó la muerte de los partidos tradicionales; la puesta de lado de la legalidad existente, la aprobación de una nueva Constitución, y la aparición de una nueva generación en todo orden de cosas: tanto en lo político como en lo cultural y lo económico. Significó también la modernización del país, la ruptura de nuestra dependencia con Inglaterra y los nuevos lazos con el nuevo coloso: los Estados Unidos; àsí como varias innovaciones en lo social: el ingreso de una nueva clase media en el escenario nacional y su participación en el mundo de las letras y de la política. Sin 
embargo, no hubo grandes movilizaciones populares sino a partir de 1930, en que desaparecieron para volver a irrumpir en la década del cincuenta, esta vez con más decisión y protagonismo. De 1919 a 1930, que es el período de Leguía, está en vigencia la Constitución de 1920, que ha remplazado a la carta moderada y realista de 1860 , pero en la práctica sus disposiciones quedan en letra muerta. No obstante, hacen su aparición, al más alto nivel normativo, instituciones nuevas y defensa de viejas ideas: el Habeas Corpus, la in tangibilidad de las tierras comunales; el reconocimiento de las comunidades indígenas, la intervención del Estado en los conflictos laborales.

De 1933 a 1945 , existe un largo periodo de dictadura o guerra civil formalmente no declarada. Las instituciones funcionan en spariencia, por encima del respeto externo a la Constitución y algunas modificaciones efectuadas por la vía del plebiscito (1939) que durarán poco. En 1945, se inicia, ıcorde con la nueva época de reconstrucción de las democracias y la derrota de los fascismos, un período con grandès interrogantes, presidido por José Luis Bus.. Imante y Rivero (1945-1948). El experimento, sin embargo, nauiraga. En 1948 volvemos a la dictadura, y esto hasta 1956. En esta época aparecen por segunda vez las masas en la escena política en lo que va del siglo. Son pocos los cambios institucionales que se reclaman; más lo son los cambios sociales, entre ellos, la reforma agraria, que conlleva la modificación constitucional correspondiente, que permite pagar en bonos (1964).

Un nuevo golpe militar en 1968 inicia grandes cambios, que se cierran prácticamente una década después. La Carta de 1979 pretende recoger las grandes lecciones de la historia reciente, y además, las reformas estructurales realizadas, en cuanto tengan permanencia o principios válidos. Se prepara así una nueva Constitución, que es la que está actualmente en vigencia.

La Constitución de 1979, si bien careció de asesoría y proyectos previos (lo cual explica muchos de sus yerros y carencias). tuvo la ventaja sobre sus predecesoras de nutrirse de un nuevo estado de cosas que estuvo ausente en épocas pasadas: por un lado el avance arrollador de los derechos humanos (que se inicia, en reali- 
dad, con la finalización de la Segunda Guerra Mundial y más en concreto con la Declaración Universal de 1948), y por otro el nuevo rostro del país después de varios años de cambios y modificaciones sustanciales. Al haberse purificado el sistema electoral y renovado el registro correspondiente, la votación es realmente representativa. En el seno de la Asamblea Constituyente, hubo una pluralidad de partidos, grupos y facciones, que hicieron el texto, a veces ambiguo, pero decididamente pluralista. Lo que no impide reconocer la existencia de algunas lagunas e imperfecciones, que podrán subsanarse en una futura reforma constitucional.

La actual Constitución sancionada en 1979, pero puesta en vigor recién en 1980, ha soportado la prueba de los últimos años, que no es mucho tratándose de textos constitucionales. La sociedad ha crecido, el aparato del Estado ha sido desbordado, el flagelo de ta crisis económica y la acción terrorista golpean la institucionalidad. Es difícil saber que puede pasar en estas circunstancias. pero es evidente que la elite polftica tiene interés en mantener el sistema, respetar sus cauces, y observar el pluralismo político y económico que ha consagrado la Carta. Es de esperar, por tal motivo, que la institucionalidad sea conservada y que esta Constitución sea la que oriente la vida política de los próximos años.

\section{Bibliografia fundamental}

La historia del derecho constitucional peruano es un género que prácticamente no ha sido cultivado. El primer intento en hacerlo se debe a Toribio Pacheco (Cf. Cuestiones constitucionales, Arequipa 1854) al que siguió Manuel Atanasio Fuentes con su Derecho constitucional universal e historia pública peruana, 2 vols., Imprenta del Estado, Lima 1874. Más recientemente puede señalarse a José Pareja Paz-Soldán (Cf. Historia de las constituciones nacionales, Lima 1944), que luego ha incluido en su Derecho constitucional peruano, Lima 1966. Pareja por otro lado ha juntado toda la parte histórica con una excelente compilación de todos nuestros textos en su libro Las constituciones del Perú, Ediciones Cultura Hispánica, Madrid 1954 (con prólogo de M. Fraga Iribarne) que sigue siendo hasta ahora el mejor tratamiento integral de nuestro proceso constitucional, aun cuando incompleto, pues los últimos 
años no los cubre, y cuando lo hace en la última edición de su Derecho constitucional peruano, es demasiado sumario. Esquemáticos, pero de interés, son los trabajos de Lizardo Alzamora, en especial Evolución política y constitucional del Perú independiente, Lib. e Imp. Gil, Lima 1942 y Programa razonado de Derecho Constitucional del Peri (Historia constitucional del Peri) Imp. Gil, Lima 1944. En fecha más reciente Juan Vicente Ugarte del Pino ha publicado una Historia de las constituciones del Perú, Editorial Andina, Lima 1978, que es previa a la actual constitución, y que más que historia (trae tan sólo apuntes o ligeros comentarios para cada época) es una valiosa compilación documental que contiene todos los tex tos constitucionales incluyendo el de Cádiz. No obstante el valor de estos antecedentes, no se cuenta todavía con un panorama global de todo nuestro proceso, que alcance incluso a la constitución actual; dentro de esta escasez lo más rescatable son los trabajos de Pareja Paz-Soldán.

En cuanto a las fuentes mismas, debemos mencionar las publicaciones oficiales de los textos; la más completa, aun cuando atrasada, es la realizada por Juan Olivo y publicada por la Cámara de Diputados (Cf. Constituciones politicas del Perú, Imp. Torres Aguirre, Lima 1922) que puede ser completada con la edición oficial de la Carta de 1920 (edic. de la Cámara de Diputados, Lima 1930) así como las correspondientes a las constituciones de 1933 (Cámara de Diputados, Lima 1967) y 1979 (edición del Ministerio de Justicia, Lima 1981).

En cuanto a los debates, cf. para la de 1920, Diario de los Debates de la Asamblea Nacional de 1919. 2 vols. Lima 1920; para la Constitución de 1933, el Diario de los Debates del Congreso Constitul ente de 1931, varios volúmenes, en especial los tomos 1, 2, 3, 4, 6, 7, 8, y 10; la Carta de 1979, cf. Diario de los Debates de la Asamblea Constituyente de 1978, 8 vols, Lima 1979-80; a los que hay que agregar los dos volúmenes de la Comisión Principal de Constitución de la Asamblea Constituyente (actas de las sesiones y anexos y ponencias).

Para un trasfondo histórico, resulta inapreciable la Historia de la República del Perú de Jorge Basadre (sétima edición, póstuma, 
11 tomos, Lima 1983); la obra sin embargo sólo cubre hasta 1933. Con posterioridad a esta fecha existen trabajos parciales sin la unidad de conjunto, salvo algunos enfoques globales de orden político o sociológico, como pueden ser F. Bourricaud, Poder y socic dad en el Perí contemporáneo, Buenos Aires 1967; F. Pike The modern history of Peru, London 1967; Felipe de la Barra, Objetine: Palacio de Gobierno, Lima 1967: Julio Cotler, Clases, Estado y Nación en el Perí, Lima 1978; Enrique Chirinos Soto, Historia de la República, 2 vols, Lima 1986; Raúl Rivera Serna, Historia del Perú: República (1822-1968), Lima, 1974; así como la obra colectiva Historia del Peri, editorial Mejía Baca, 12 tomos, Lima 1980 (interesante pero muy desigual).

Algunos trabajos sobre este período son los siguientes; para la Carta de 1860 , puede verse, en cuanto a su génesis, Javier Vargas, La Constitución de 1860, Lima 1961 ; tratamiento sobre clla, José Silva Santisteban, Curso de Derecho Constitucional, París 1914; Luis Felipe Villarán, La Constitución peruana comentada. Lima 1899; sobre la Carta de 1920, cf. Toribio Alayza y Paz-Soldán, Derecho constitucional general y' del Perí, Lima 1928; Giraham $\mathrm{H}$. Stuart, The governamental systen of Poru, Washington 1925: sobre la Carta de 1933, cf. Toribio Alayza y Paz-Soldán, Derecho constitucional del Perí y ley'es orgánicas de la Répuiblica. Lima 1934 y José Pareja Paz-Soldán, Derecho constitucional peruano, 4ta. edición, Lima 1966. Sobre la Constitución de 1979, cf. Marcial Rubio y Enrique Bernales, Constitución y socicedad politica, Lima 1983, José Pareja Paz-Soldán, Derecho constitucional peruano y la Constitución de 1979, 3ra, edición revisada, Lima 1984 y Francisco Eguiguren P. (coordinador) La Constitución Politica de 1979 ." sus problemas de aplicación. Lima 1987.

Bibliografía y periodificación pueden verse en Ricardo Bustamante Cisneros, Constitución .1 Habeas Corpus, en Anales Judiciales, Lima 1959: Domingo García Belaunde, Guia bibliografica de Derecho constitucional pentano, en Derecho (Lima), num. 29, 1971; ib. Cuarenta años de constitucionalismo peruano en Revista de Derecho y Ciencias Politicas (San Marcos) Lima. 1-2-3, enero-diciembre de 1977: C. Herbold y Steve Stein, Guia bibliográfica para la historia social y politica del Perie en el siglo 
XX. Lima 1971 y Augusto Pérez-Rosas Cárdenas, liuentes bibliográficas pertanas en las ciencias sociales (1879-1979), Lima 1981.

Lima. junio de 1989 